\title{
APPLICATION OF THE "PREDATOR-PREY" MODEL FOR ANALYSIS AND FORECASTING THE SHARE OF THE MARKET OF MOBILE OPERATING SYSTEMS
}

\author{
${ }^{1}$ Olena Nikolaieva, Associate Professor, Cand. Phys.-Mat. of science \\ ${ }^{2}$ Yevheniia Bochko, \\ ${ }^{I}$ Ukraine, VN Karazin Kharkiv National University; \\ Department of Economic Cybernetics and Applied Economics \\ ${ }^{2}$ Ukraine, Kharkiv, Intetics Incorporation \\ Data Entry Specialist at Intetics Inc.
}

DOI: https://doi.org/10.31435/rsglobal_ijite/30062019/6527

\section{ARTICLE INFO}

Received 20 April 2019

Accepted 15 June 2019

Published 30 June 2019

\section{KEYWORDS}

operating systems of mobile devices,

model Lotka-Volterra,

competitive interaction,

predator-prey system,

equilibrium points,

forecast.

\begin{abstract}
The study is aimed to analyze the dynamic behavior of indicators of the market share of operating systems of mobile devices using the modified Lotka-Volterra model. Using the solution of an optimization problem, the coefficients of a system of differential equations in the case of two and three competitors are estimated on the basis of real statistical data, and special points and properties of data from dynamic systems are investigated. Based on the numerical integration of the obtained equations, predictions are made of the market share of mobile operating systems Android and iOS.
\end{abstract}

Citation: Olena Nikolaieva, Yevheniia Bochko. (2019) Application of the "Predator-Prey" Model for Analysis and Forecasting the Share of the Market of Mobile Operating Systems. International Journal of Innovative Technologies in Economy. 4(24). doi: 10.31435/rsglobal_ijite/30062019/6527

Copyright: (C) 2019 Olena Nikolaieva, Yevheniia Bochko. This is an open-access article distributed under the terms of the Creative Commons Attribution License (CC BY). The use, distribution or reproduction in other forums is permitted, provided the original author(s) or licensor are credited and that the original publication in this journal is cited, in accordance with accepted academic practice. No use, distribution or reproduction is permitted which does not comply with these terms.

Introduction The information sector in the global economy is a segment in which any activity is inextricably linked with the introduction and use of innovations. The "lottery" of selected innovations leads to a continuous intensification of the competition between information products, services, technologies, which leads to a change in the situation in the markets, the disappearance of certain market actors and the emergence of new players. The competition is particularly vivid in the software market for mobile devices, namely, the operating systems of mobile devices (OSMD).

As is known [1], the operating system is a type of computer software that allows you to manage computer software that provides control over the computing process, as well as user interaction. With the advent of operating systems on smart phones, tablets and other mobile devices, it became possible to launch many programs and applications under their control, in connection with which mobile devices in many ways began to duplicate desktop computers and laptops. Although experts associate the birth of the first mobile OS with DOS and Windows CE [2], the real OSMD market was developed in the first twenty years of the XXI century, when gadgets with advanced platforms and multitasking applications requiring OS management became widely us ed.

All these years in the segment of OSMD there was a fierce competition, which resulted in the displacement of some competitors from the market and a change in sales leaders. The described situation is extremely reminiscent of the struggle of species for survival in wildlife, which led to the 
idea of using a system of differential equations for modeling the OS market share of mobile devices, describing the dynamics of predator and prey population in evolutionary biology.

Thus, the purpose of this article is to study the competitive interaction in the market of mobile operating systems, as well as forecasting the market share of competing systems using modified predator-prey mathematical models.

Review of literature and data sources. The model that laid the foundation for mathematical theories of evolutionary dynamics is the model of the dynamics of the number of two populations of A. Lotka and V. Volterra by the name of two scientists who published it almost simultaneously in 1925 and in 1926 [3]. The model is a system of differential equations describing the dynamics of the number of two populations of predators and prey.

$$
\begin{aligned}
& \frac{d x_{1}}{d t}=r_{1} x_{1}-\alpha_{12} x_{1} x_{2} \\
& \frac{d x_{2}}{d t}=-r_{2} x_{2}+\alpha_{21} x_{1} x_{2} .
\end{aligned}
$$

In model (1) - (2) $x_{1}$ and $x_{2}$ - the number of preys and predators, respectively; $r_{1}$ is the rate of reproduction of preys in the absence of predators; $r_{2}$ is the natural mortality of predators; $\alpha_{12}$ - specific rate of prey predation; $\alpha_{21}$ is the specific multiplication factor of predators.

Later, model (1) - (2) was extended to the case of several populations and modified to take into account additional conditions (in particular, competition for a resource). In the most general form, the model of the dynamics of multiple species populations can be written in the form of equation (3)

$$
\frac{d x_{i}}{d t}=f_{i}\left(x_{1}, \ldots x_{n}, M\right)
$$

where $x_{\mathrm{i}}=x_{\mathrm{i}}(t), i=1, \ldots, \mathrm{n}$ is the number of individuals of the $i$-th species, $M$ is the set of parameters. If $M$ is clearly independent of time, then (3) is a system of autonomous differential equations.

Autonomous systems of population dynamics were studied by A. Kolmogorov, G. Gauze, M. Rosenzweig, KS Holling, V. Arnold, A. D. Bazykin, G. Y. Riznichenko. The most famous models that describe the dynamics of the interaction of two or more populations. The most common and well studied are such interaction cases as interspecific competition (the number of growth of each species slows down in the presence of the other); symbiosis (when species help each other grow) and predatorprey (when the number of individuals of one species grows, and the other falls).

Models of competitive interaction of the "predator-prey" type are widely used for the analysis of economic processes and phenomena. Enterprises, industries, brands, products, technologies can compete with each other in time. Analogues of the population size indicator in models with economic applications can be the volume of production, capital, profits, profitability, the number and value of shares, the number of customers and so on. Models of evolutionary economics, and in particular, the modified Lotka-Volterra model are successfully used to analyze the development of Internet resources: social networks, commercial websites, web services, etc.

One of the pioneering work in this direction was the work of S. Maurer and B. Guberman [4], in which the task of studying the change in the number of users of web projects was considered. In [4], the assumption was made that the number of users varies not only because of the attractiveness of the web project itself, but also under the influence of competing sites offering similar services. The "predator-prey" model in the formulation of Maurer-Huberman is written as follows:

$$
\frac{d y_{i}}{d t}=a_{i} y_{i}\left(b_{i}-y_{i}\right)-\sum_{j \neq i, j=1}^{n-1} c_{i j} y_{i} y_{j},
$$

where $y_{i}$ is the share of the total number of users of the $i$-th $\left.(i=\overline{1, \mathrm{n}})\right)$ website, $a_{i}$ is the growth rate of the number of users of the $i$-th website, $b_{i}$ is the capacity of the $i$-th website (the number of simultaneous connections that can be supported when using the site), $c_{i j}$ is the level of competition between sites (the rate at which users stop visiting the $i$-th site). 
Model (4) was analyzed by the authors for the case of two sites with arbitrary values of constants and with values of constants $a_{1}=a_{2}=1, b_{1}=b_{2}=1, c_{12}=c_{21}=c$. Also in [4], the case of $\mathrm{n}$ sites with constraints was considered $\left(\left(a_{i}=a, b_{i}=b, c_{i j}=c\right)\right)$. In all the above situations, the equilibrium states of the systems were studied and it was concluded that in all cases, with strong competition (c> ai), one site was the winner in the struggle for existence.

In their work, S. Maurer and B. Guberman also investigated the influence of the competition parameter on the dynamics of the number of site users (a system of 16 sites was considered). It turned out that in the case of weak competition, the coexistence of sites on the market is possible, and for a strong one, a monopolist site appears. In the case of $c \approx 1$, the transition to equilibrium does not occur.

The theoretical conclusions of [4], obtained for model situations, were confirmed by studies conducted in [5], where statistical data on visits to real Internet sites were processed.

In [6] and [7], improvements to the Maurer-Huberman model were proposed. The authors [6] L. Yanhui and Z. Siming used model (4) to study the competitive interaction of e-commerce sites. They introduced into the model an additional member, which took into account the influence of the choice of websites with a large audience of users. R. Yawei, J. Deli, D. Hinjun in [7] proposed to include in the model (5) the separation of users into visitors and regular users of the site. They showed that the victory in the competition in the face of strong competition is achieved by the site, only if a significant proportion of visitors to the site are its permanent users.

In the works of K. Kononova [8], [9], the Lotka-Volterra model in the modification of MaurerHuberman was used to solve the problem of assessing the analysis of the dynamics of the number of users of social networks. On the basis of empirical data, K. Kononova parametrized the coefficients of equations for systems of two and three differential equations that simulate the competitive behavior of two or three social networks. The equilibrium points of the mentioned systems were found and the behavior of the solution trajectories in time was characterized, which in the period under study describes the dynamics of real data quite well.

Note that we have not found in the literature examples of the use of the Lotka-Volterra model or its modifications for analyzing and predicting the market share of operating systems for mobile devices. There are also extremely few articles in which other methods are used for the same purpose. For example, Australian scientists H. Kaur and M. Abodallahian [10] used Holt's exponential smoothing method to predict the market share of operating systems for mobile devices, which showed satisfactory results. The confidence interval for iOS was wider than for Android, however, in general, the forecast accuracy is indicated by the fact that the p-values for both forecast models are small. Monthly data taken for the period from 2000 to 2012 was used for forecasting, and the levels of time series for 2013 were used to test predictive models. In our article [11], to predict the share of the OSMD market, a quarterly sample of data from 2010 to 2015 was taken and trend models, adaptive forecasting methods, neural network apparatus and seasonal decomposition methods were used. For predicting the market share of Android, the best results were shown using neural networks, and for iOS, the seasonal decomposition method.

As data sources, we used Statista [12] and Statcounter [13] statistical portals. At the first of them, quarterly information for the period from 2010 to the second quarter of 2018 is presented. Statcounter provides monthly information on the market share of mobile OS as a share taken from the number of sales of devices with operating systems installed on them. There is a difference between the data on the first and second statistical portal. The share of Android on Statista is 5-10\% higher than the same figure taken on Statcounter. Accordingly, the share of iOS, the closest competitor of Android, is higher by Statcounter and lower by Statista. This discrepancy in the data can be explained by the fact that Android is an open source operating system and it is impossible to accurately track the number of sales of devices to third-party developers. iOS, by contrast, is a closed-source operating system and application development under its control is strictly regulated by Apple.

Analysis/study/results. The subject of this research is the analysis of the dynamic behavior of the market share of operating systems of mobile devices using the Lotka-Volterra model. The life cycle of the studied indicator is most vividly shown for the most popular in the last decade OSMD is displayed on graphs based on empirical data taken from the site [12] (Fig. 1).

Fig. 1 also shows how dramatic the past eight years have been for information products of this type. Now the undisputed market leader is the Android OS, and its closest competitor, iOS, confidently holds an average of $15 \%$ of the global market share throughout the period under review. 
However, the Symbian OS market share is approaching zero, whereas in 2010 it was the hallmark of Nokia and Sony Ericsson, ranked first in sales and was far ahead of Android. And paradoxically, the transition to the open code was the beginning of the end for Symbian, while this fact contributed to the flourishing of Android. The mobile OS Bada did not justify hopes that had been pinned on it, and in 2013 Samsung, which had been releasing it since 2009, announced it would cease to exist.

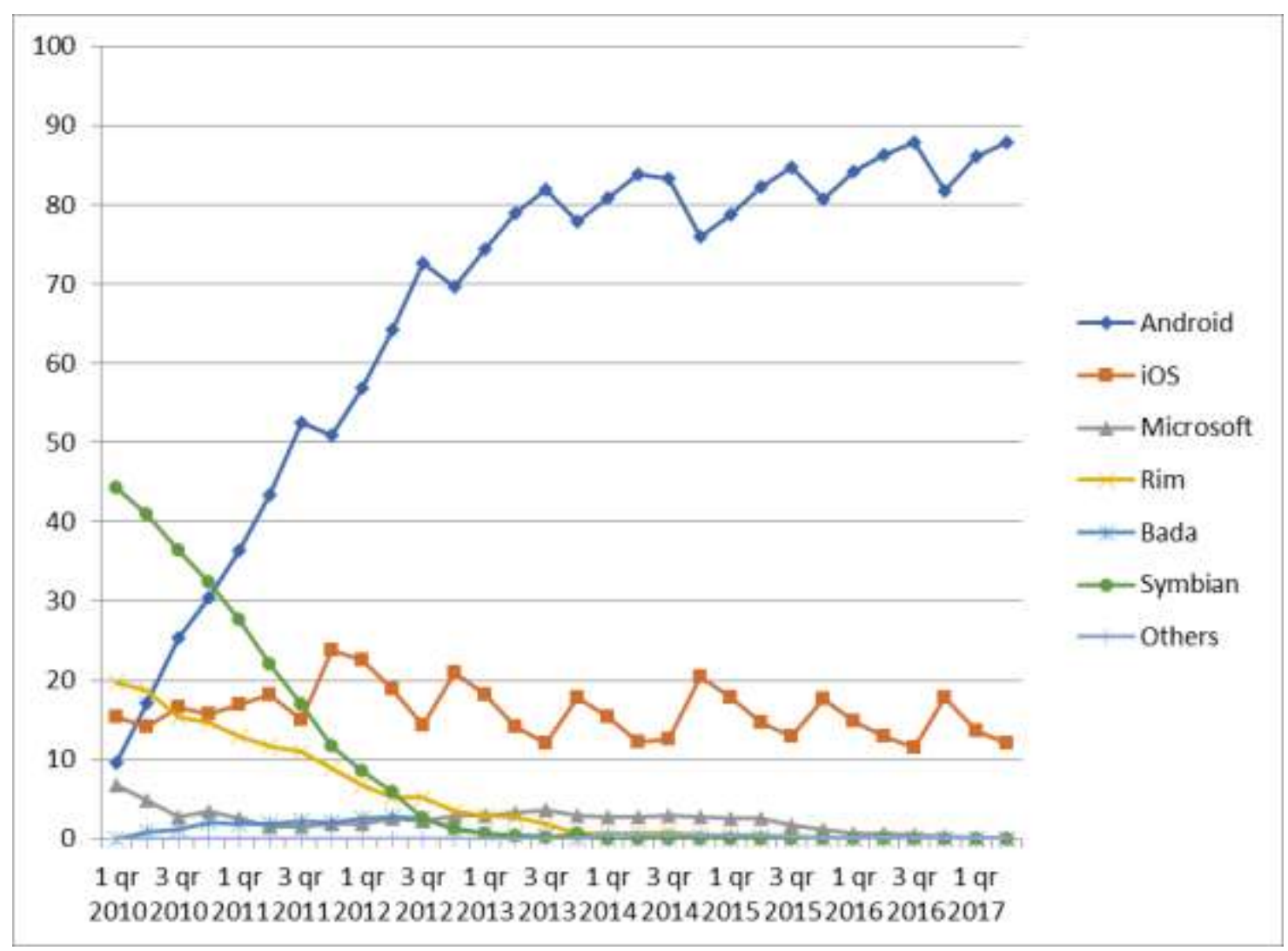

Fig.1. The share of mobile operating systems in the global market

Thus, in the segment of mobile operating systems in the period under review, fierce competition was observed. Consequently, to model the dynamics of the share of these information products, it is possible to use systems of predator-prey type equations in the interpretation of MaurerHuberman. After all, for mobile operating systems, Maurer's assumption that the demand for an operating system of a certain brand changes not only due to its own properties of the system, but under the influence of other OSMD offering similar services, will be fair.

In order to write the equations of the model and their subsequent solution, it is necessary to determine the coefficients in the equations (4), corresponding to the dynamics of real indicators. If the coefficients $a_{i}(i=1, \ldots, \mathrm{n})$ correspond to the average growth rate of $\mathrm{n}$ operating systems competing and can be easily calculated based on the available time series, then the capacity parameters $\mathrm{b}_{i}$ and competition $c_{\mathrm{ij}}$ are not easy to determine based on the properties system. Therefore, to carry out computational experiments with real data, the approach proposed by K. Kononova in [8], [9] was used.

According to this approach, first, for two or three competitors, by finding stationary points, the general properties of the system are investigated, and then to identify unknown parameters ai, bi, cij, an approximate solution of the following optimization problem is found

$$
\begin{gathered}
J=\sum_{j=1}^{n} \sum_{k=1}^{m}\left(y_{j k}-y_{j k}^{\ni}\right)^{2} \rightarrow \min \\
\frac{d y_{i}}{d t}=a_{i} y_{i}\left(b_{i}-y_{i}\right)-\sum_{j \neq i, j=1}^{n-1} c_{i j} y_{i} y_{j} . \\
a_{i} \geq 0, c_{i j} \geq 0,0 \leq b_{i} \leq 1 .
\end{gathered}
$$


The sum of squared deviations between the empirical data and the points of the "optimal" trajectory, which satisfy the constraints in the form of differential equations of the model (4), is minimized. An approximate solution of the above problem can be obtained using the pseudospectral collocation method (with Gauss or Chebyshev points) implemented in Tomlab PROPT. Tomlab PROPT is a software package based on MATLAB, which is used for solving applied problems of optimal control and estimation of parameters of dynamic systems [14].

Before estimating model parameters in computational experiments, special points of systems with the dynamics of two and three competitors were investigated.

In general, the system with the participation of two competitors will be as follows:

$$
\left\{\begin{array}{l}
d y_{1} / d t=a_{1} y_{1}\left(b_{1}-y_{1}\right)-c_{12} y_{1} y_{2} \\
d y_{2} / d t=a_{2} y_{2}\left(b_{2}-y_{12}\right)-c_{21} y_{1} y_{2}
\end{array}\right.
$$

System (6) has four equilibrium points ( $0 ; 0) ;\left(b_{1} ; 0\right) ;\left(0, b_{2}\right) ;\left(\frac{a_{2}\left(a_{1} b_{1}-b_{2} c_{12}\right)}{a_{1} a_{2}-c_{12} c_{21}}, \frac{a_{1}\left(a_{2} b_{2}-b_{1} c_{21}\right)}{a_{1} a_{2}-c_{12} c_{21}}\right)$, whose stability conditions are given in [11]. The point $(0 ; 0)$ is unstable, and the remaining critical points will be stable if certain conditions on the coefficients of system (6) are satisfied. In particular, for the subsequent analysis it is important that the stability condition of the fourth equilibrium point

$$
b_{2} / b_{1}>c_{21} / a_{2}, b_{1} / b_{2}>c_{12} / a_{1} \text {. }
$$

Fulfillment of this condition means that competitors can coexist.

In the first computational experiment, using the approximate solution of the optimization problem (5), the model parameters for two competitors, Android and iOS, were estimated. The following system of equations was obtained

$$
\left\{\begin{array}{c}
\text { Android: }{ }^{d y_{1}} / d t=0,3258 y_{1}-0,004 y_{1}^{2} \\
\text { iOS: }{ }^{d y_{2}} / d t=0,2795 y_{2}-0,0108 y_{2}^{2}-0,0015 y_{1} y_{2}
\end{array}\right.
$$

An analysis of the system of differential equations (8) shows that although the growth rate of the Android OS is lower than the growth rate of the iOS OS $\left(a_{1}=0,004 ; a_{2}=0,0108\right)$, Android has more capacity than $\left.\operatorname{iOS}\left(b_{1}=81,45 ; b_{2}=25,88\right)\right)$, and both competitors do not have a strong influence on each other $\left(a_{1}>c_{12}=0 ; a_{2}>c_{21}=0,0015\right)$. It is important that condition (7) is satisfied for the coefficients of system (8). Thus, at the model level, the long coexistence of two competing mobile operating systems in reality is confirmed.

In fig. 2 shows the points of calculated and real market shares of both OSMD. Tables 1 and 2 show the forecast values of the market share of Android and iOS.

Table 1. Comparison of actual and forecast values of the market share of Android OS

\begin{tabular}{|c|c|c|c|}
\hline Period & Actual share of Android, \% & $\begin{array}{c}\text { Forecast share of Android, } \\
\%\end{array}$ & $\begin{array}{c}\text { Point Approximation } \\
\text { Error }\end{array}$ \\
\hline 1 qr 2016 & 75,5 & 81,34 & 0,077 \\
\hline 2 qr 2016 & 77,35 & 81,37 & 0,052 \\
\hline 3 qr 2016 & 78,40 & 81,39 & 0,038 \\
\hline 4 qr 2016 & 71,60 & 81,41 & 0,137 \\
\hline 1 qr 2017 & 71,72 & 81,42 & 0,135 \\
\hline 2 qr 2017 & 72,47 & 81,42 & 0,124 \\
\hline 3 qr 2017 & 73,21 & 81,43 & 0,112 \\
\hline 4 qr 2017 & 73,23 & 81,43 & 0,112 \\
\hline 1 qr 2018 & 71,42 & 81,44 & 0,14 \\
\hline
\end{tabular}


Table 2. Comparison of actual and forecast values of the market share of iOS OS

\begin{tabular}{|c|c|c|c|}
\hline Period & Actual share of iOS, $\%$ & Forecast share of iOS, $\%$ & $\begin{array}{c}\text { Point Approximation } \\
\text { Error }\end{array}$ \\
\hline 1 qr 2016 & 19,29 & 18,09 & 0,061 \\
\hline 2 qr 2016 & 19,25 & 18,14 & 0,057 \\
\hline 3 qr 2016 & 19,78 & 18,17 & 0,081 \\
\hline 4 qr 2016 & 18,95 & 18,20 & 0,039 \\
\hline 1 qr 2017 & 19,56 & 18,23 & 0,067 \\
\hline 2 qr 2017 & 19,51 & 18,25 & 0,064 \\
\hline 3 qr 2017 & 19,49 & 18,26 & 0,062 \\
\hline 4 qr 2017 & 20,08 & 18,27 & 0,089 \\
\hline 1 qr 2018 & 26,20 & 18,29 & 0,302 \\
\hline
\end{tabular}

In order to obtain predicted values for subsequent periods, numerical integration of system (8) was carried out with the help of Matlab solvers. Solvers ode23, ode113, ode 45 , ode23t and ode15s were used. A change in the type of solver only affected the third decimal place, and such accuracy was not necessary in this task. The forecast results given in the tables were obtained using the ode 45 solver, which implements the 4th and 5th Runge-Kutta method. The average approximation error over the entire interval for Android is $7 \%$, and for iOS it is $14 \%$. Outside the prediction interval for the data in Tables 1 and 2, it was $10 \%$ for both OSs.

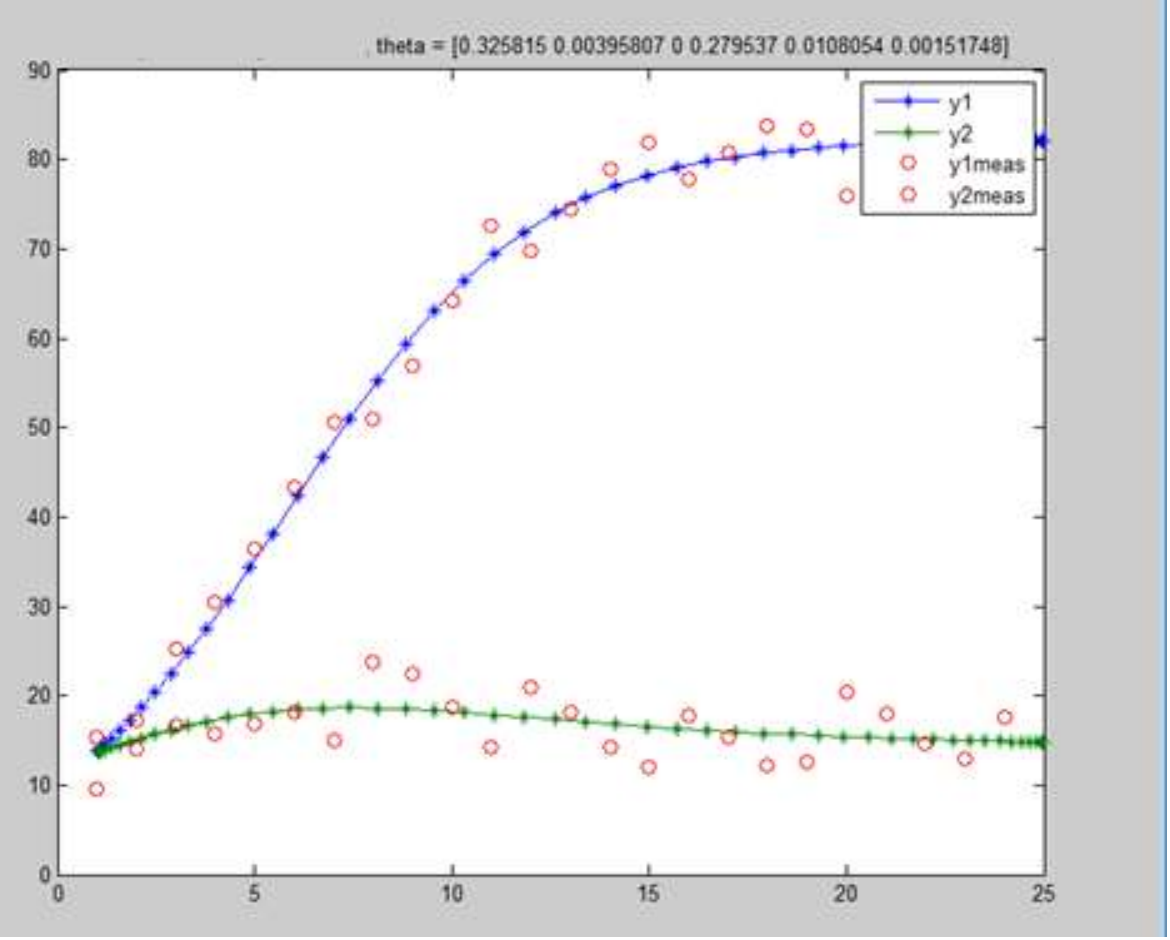

Fig.2. Actual (indicated by circles) and calculated (upper curve - Android, lower - iOS) values of market shares of both competitors from the first quarter of 2010 to the fourth quarter of 2015 (the period number is shown on the $X$ axis)

Let us analyze the characteristics of the predator-prey system for three competitors Android, iOS and OSMDs, developed by Microsoft. To reveal the behavior of phase trajectories in the vicinity of the critical point, one needs to construct the Jacobian J of the first approximation system for system 
(4) and calculate the values of the first element at the critical points. Then it is necessary to solve the characteristic equation $\operatorname{det}(\mathrm{J}-\lambda \mathrm{E})=0=0$, and by the values of its roots $\lambda_{1}, \lambda_{2}, \lambda_{3}$ to draw a conclusion about the type of the singular point.

All these calculations for the system of three competitors (5) in general were done in the thesis work of Eugenia Bochko and obtained formulas relating the values of critical points with the coefficients of the model. Here, due to space limitations, they are not given. However, it is possible to analyze the singular points, knowing the coefficients of the system of differential equations estimated by the Tomlab program for three competitors. After minimizing the functional (5) for the case of three market participants, the following system of differential equations was obtained:

$$
\left\{\begin{array}{c}
\text { Android: } d y_{1} / d t=0,3324 y_{1}-0,004 y_{1}^{2} \\
\text { iOS: } d y_{2} / d t=1,6515 y_{2}-0,0067 y_{2}^{2}-0,0123 y_{1} y_{2}-0,2923 y_{2} y_{3} \\
\text { Microsoft: } d y_{3} / d t=0,0303 y_{3}-0,0303 y_{3}^{2}-0,0303 y_{3} y_{1}-0,0303 y_{3} y_{2}
\end{array}\right.
$$

Table 3 shows the actual values $\lambda_{1}, \lambda_{2}, \lambda_{3}$ for each of the seven singular points and the type of the phase portrait is determined.

Table 3. Equilibrium points of the system (9)

\begin{tabular}{|l|l|l|}
\hline Equilibrium point & Jacobian characteristic numbers & $\begin{array}{l}\text { The type of Equilibrium } \\
\text { point }\end{array}$ \\
\hline$(0 ; 0 ; 0)$ & $\lambda_{1}=0,3324, \lambda_{2}=1,6515, \lambda_{3}=0,0303$ & Unstable node \\
\hline$(831 ; 0 ; 0)$ & $\lambda_{1}=-0,3324, \lambda_{2}=-8,5698, \lambda_{3}=-25,149$ & Stable node \\
\hline$(0 ; 246,49 ; 0)$ & $\lambda_{1}=0,3324, \lambda_{2}=-1,6515, \lambda_{3}=-7,4385$ & Saddle point \\
\hline$(0 ; 0 ; 1)$ & $\lambda_{1}=0,3324, \lambda_{2}=1,3592, \lambda_{3}=-0,0303$ & Saddle point \\
\hline$(831 ; 0 ;-830)$ & $\lambda_{1}=-0,3324, \lambda_{2}=234,0392, \lambda_{3}=25,149$ & Saddle point \\
\hline$(831 ; 0 ;-1279,07)$ & $\lambda_{1}=-0,3324, \lambda_{2}=8,5698, \lambda_{3}=13,60696$ & Saddle point \\
\hline$(831 ;-455,84 ;-8,818)$ & $\lambda_{1}=0,3324, \lambda_{2}=0,1162, \lambda_{3}=-10,80$ & Saddle point \\
\hline
\end{tabular}

In model (9), there is a lack of competitive pressure on OSMP Android from iOS and Microsoft. It is interesting, that the growth rate of Android remained the same as it was in the system for two competitors, but the growth rate of OSMD iOS compared with the case of two market participants decreased. In the second equation of system (9), the relatively high coefficients $c_{21}$ and $c_{23}$ are responsible for competitive interaction. Therefore, iOS is experiencing severe pressure from Android and Microsoft. Windows OSMD has a rather low growth rate (0.0303) and its dynamics is downward, which can be explained not only by the pressure of competitors, but also by the internal properties of the system itself (meaning errors and miscalculations made in the development and positioning of mobile operating systems from Microsoft.). Figure 3.

Actual and calculated data on the share of the total market of each competitor are presented in

The dynamic behavior of the trajectories, which we observe in Figure 3, seems to correspond to the third critical point of Table 3, since the two trajectories from Figure 3 are stable, and the lower one is clearly unstable and tends to zero over time. This is quite consistent with the real situation in the life of mobile operating systems developed by Microsoft, which include Windows Phone, Windows Mobile, Windows 10 Mobile. Currently, their development and active support has been discontinued by Microsoft [17]. 


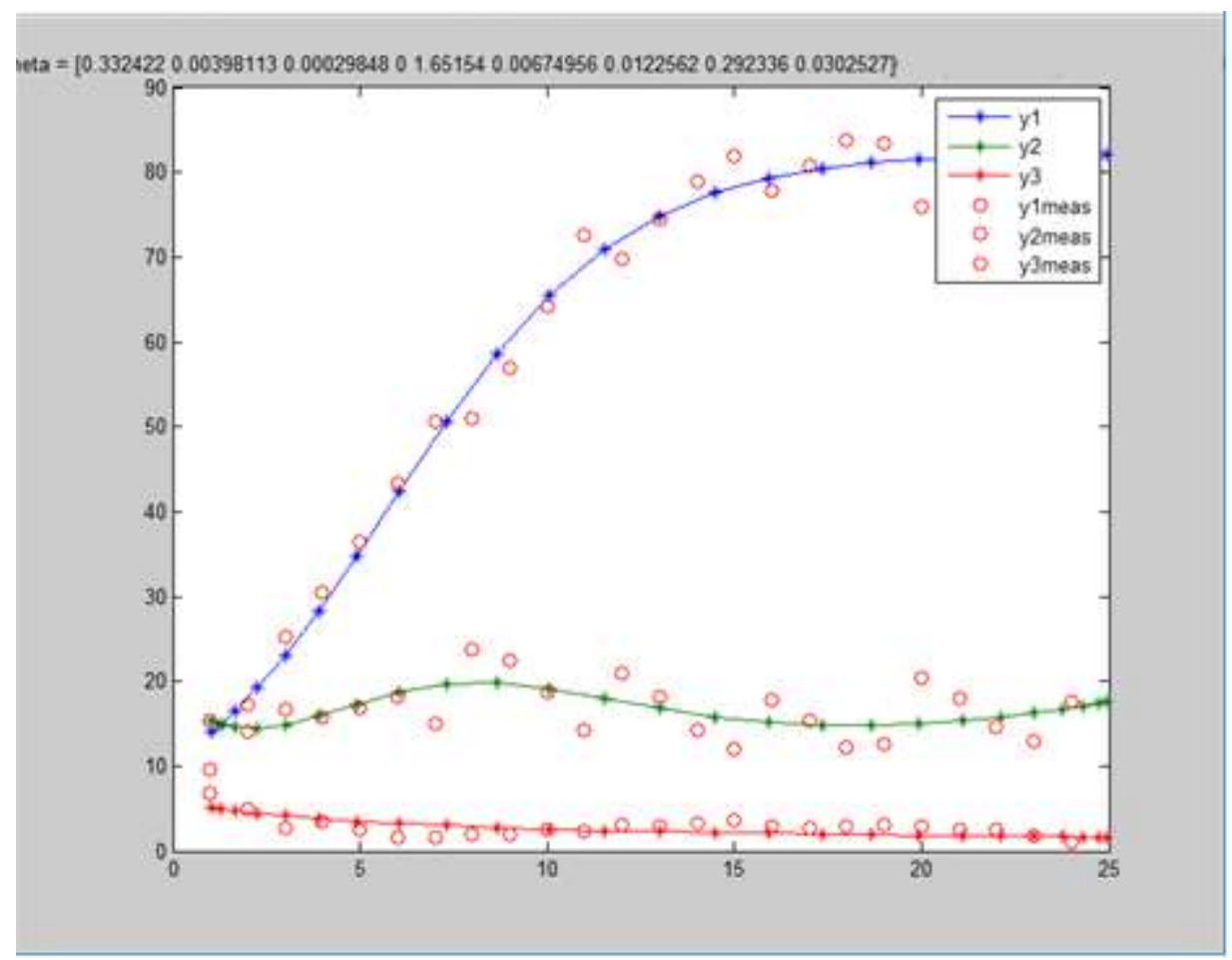

Fig. 3. Actual (indicated by circles) and calculated values of the market shares of both competitors from the first quarter of 2010 to the fourth quarter of 2015 (the number of the period is shown on the $X$ axis). The upper curve is Android, below is iOS, the lowest is OSMD, developed by Microsoft.

Indicator of the accuracy of approximation of real values calculated on the considered time interval is the average approximation error. For Android, it is 13\%, for iOS - 14, for Microsoft - 43\%. Thus, the quality of modeling for the case of three competitors is worse than for two, however, the model correctly describes the fundamental tendencies in the development of OSMD.

Conclusions. The beginning of the tenths of the 21 st century was an era of storm and an onslaught for the developers of mobile devices and operating systems for them. Innovations in technology, the emergence of new platforms, the desire of large concerns-producers of telephones and communicators to create their own operating systems led to a fierce competition for market superiority. Therefore, the study of the features of market competition between OSMDs using mathematical modeling is an interesting and urgent task. This article uses the modified Lotka-Volterra model (predator-prey model) for these purposes.

Currently, the situation on the mobile OS market has stabilized and is close to a duopoly: the market is divided between the Android and iOS operating systems. The results of this study confirm these trends in market dynamics. In general, predator-prey models for analyzing and predicting various aspects of the struggle for existence in the markets of operating systems for mobile devices showed satisfactory predictive ability and suitability for practical use.

\section{REFERENCES}

1. Таненбаум Э., Бос Х. Современные операционные системы. СПб.: Питер, 2015. - 1120 с.

2. Сергей Стельмах. ОС для смартфонов: путь длиною в 22 года. IT Week, 30.03.2015 Available in https://www.itweek.ru/mobile/article/detail.php?ID=172850

3. Вольтерра В. Математическая теория борьбы за существование. М., 1976. 286 с.

4. Maurer S.M., Huberman B.A. (2000), 'Competitive Dynamics of Web Sites', Available in <arXiv:nlin.CD/0003041>

5. Adamic L.A. (1999) The nature of markets of World Wide Web, Q.J.Electron. Comerce // L.A. Adamic,

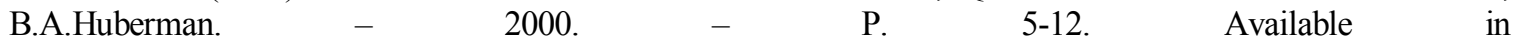
https://www.labs.hp.com/research/idl/papers/webmarkets/webmarkets.pdf

6. Yanhui L. (2007) Competetive Dynamics of e-commerce Web sites. /lLiYanhui, ZhuSiming //Applied Mathematical Modelling. 2007. May. 5(31): 912-919. Available in https://www.sciencedirect.com/science/article/pii/S0307904X06000631 
7. Yawei R. Websites Competitive Model with Consumers Divided Into Users and Visitors [Electronic Resource] / R. Yawei, Y. Deli, D. Xinjun // 4th International Conference Wireless Communications, Networking and Mobile Computing. -2008. -P. 1-4. - Available in: http://www.researchgate.net/publication/251865194_Websites_Competitive_Model_with_Consumers_Divi ded_Into_Users_and_Visitors

8. Kateryna Kononova. Social Networks: Modeling of Competitive Interaction // Procedia Economics and Finance. Amsterdam, 2012, 1: 249-258. Available https://www.sciencedirect.com/science/article/pii/S2212567112000299

9. Кононова К.Ю. Інформаційна економіка: моделювання еволюційних процесів. Х., 2015. 312 с.

10. Kaur H., Abodallahian M. Analytical Study of Global Mobile Market: Forecasting and Substitution / H.Kaur, M.Abodallahian //11th International Conference on Information Technology: New Generations, Las Vegas, NV. 2014: 485-489. Available in: http://ieeexplore.ieee.org.

11. Ніколаєва О.Г, Бочко С.А. Моделювання та прогнозування попиту на інформаційні продукти / О.Г. Ніколаєва, Є.А. Бочко //Науковий вісник Міжнародного гуманітарного університету. Одеса, 2017. 23-2: 138-142. Available in http://vestnik-econom.mgu.od.ua/journal/2017/23-2-2017/31.pdf

12. https://www.statista.com/statistics/266136/global-market-share-held-by-smartphone-operating-systems/

13. http:/gs.statcounter.com/os-market-share/mobile/worldwide

14. Tomlab optimization [Electronic resource]: Tomlab Manuals. - Access mode: http://tomopt.com/tomlab/download/manuals.php.

15. https://support.microsoft.com/en-us/help/4485197/windows-10-mobile-end-of-support-faq 